Open Access

\title{
Income inequality and privatisation: a multilevel analysis comparing prefectural size of private sectors in Western China
}

Nan Zou Bakkeli

\author{
Correspondence: \\ n.z.bakkeli@sosgeo.uio.no \\ Department of Sociology and \\ Human Geography, University of \\ Oslo, Postboks 1096 Blindern, Oslo \\ 0317, Norway
}

\begin{abstract}
In 2000, the Chinese government initiated a campaign to develop Western China and reduce local and regional inequality. Privatisation has been a central component of the campaign. This article studies the relationship between privatisation and income inequality in Western China, based on survey data from 11 Western provinces collected between 2004 and 2005. This study first explores the link between privatisation and income inequality at the prefecture level, investigating whether a higher degree of privatisation can be linked to increased income inequality. Using multilevel random coefficient modelling, it then studies whether the impact of an individual's socioeconomic position on their income varies across regions with different degrees of privatisation. The final part presents simulations of economic inequality based on the random slope model. The study shows that income inequality is higher in regions with higher degrees of privatisation, and larger privatisation correlates with lower individual income. Furthermore, the study confirms that individual income is strongly affected by education, occupation, employment sector and household registration status. Income differences based on these factors do not vary with the level of privatisation; however, a finding that contradicts market transition theory in the context of Western China.
\end{abstract}

Keywords: Income inequality, Privatisation, Market transition

\section{Introduction}

Since the economic reforms initiated in the 1980s, China has experienced rapid economic and social development, as well as rising inequality. This has led to an increased focus on the relationship between market reforms and social stratification. There is, for example, a large body of literature which examines the effects of marketisation on education inequality, labour market conditions and wage/income inequality (Mok, Wong, and Zhang 2009; Mok 2012; Zhao and Qiu 2012). In Western China, an important research question is whether the reform measures implemented in Western China have contributed to increased income inequality. Specifically, questions arise as to how social structures, such as differences in education level, occupation class and employment sector, are influenced by privatisation processes and how this in turn results in differences in individuals' income levels.

(C) The Author(s). 2017 Open Access This article is distributed under the terms of the Creative Commons Attribution 4.0 International License (http://creativecommons.org/licenses/by/4.0/), which permits unrestricted use, distribution, and reproduction in any medium, provided you give appropriate credit to the original author(s) and the source, provide a link to the Creative Commons license, and indicate if changes were made. 
In this paper, we explore the relationship between institutional differences and stratification by studying how privatisation, defined as the size of the private sector within regions in Western China, is associated with income inequality. Using the Monitoring Social and Economic Development in Western China (MEDOW) survey data covering more than 167,000 individuals in 44,738 households collected between 2004 and 2005, we investigate how the level of privatisation, measured as the size of private sectors in 128 Chinese prefectures, is associated with income inequality. The analysis is completed in three stages. First, the relationship between privatisation and income inequality at prefecture level is mapped out. This stage involves the estimation of the overall correlation between the Gini coefficient and the prefecture-level variables. In the second stage, multilevel modelling is used to analyse the relationship between privatisation, several measures of individual socioeconomic status and individual income. In the third stage, this link is explored by simulating how aggregated income inequality at the prefecture level is affected by varying degrees of privatisation, based on the results from stage two. By comparing the simulated and actual measures of income inequality, we may verify the importance of central income determinants, examine model fits and test the relevance of regional variation.

This paper contributes to the existing literature in several ways. First, unlike most other studies that focus on general economic reforms or economic development in China, it highlights the impact of privatisation on income inequality. Second, the study takes advantage of a unique and rich survey data set collected in Western China, from a period when Western China was still in the transition phase to a more market-oriented economy. It thus revisits market transition theory in a specific historical and regional context. Third, the study uses a more concrete indicator of marketisation, namely the proportion of private sector employment. This measure is likely to be less confounded by the degree of economic development compared to measures such as GDP.

\section{Privatisation and income inequality in China}

An important aspect of the economic reforms since the early 1980s has been the introduction of market principles. Central policies include the downsizing of state enterprises, the establishment of a private sector and the reduction and privatisation of welfare (Naughton 2007). Marketisation describes processes in which market mechanisms replace state-planned economic activities and allocation of resources (Wu and Xie 2000, 6). However, explaining socioeconomic stratification based on the broad concept of marketisation can be challenging. It is difficult to capture how marketisation is defined, measured and delimited. There is also a risk of ecological fallacy of drawing conclusions about individual level outcomes based on aggregated social factors. Therefore, this study aims to narrow the focus down to a more concrete, but also central, component of marketisation, namely privatisation.

Privatisation has been a central aspect of the reform processes in China. It primarily refers to state-owned enterprises passing under private ownership (Jefferson and $\mathrm{Su}$ 2006), in addition to the growth of the private sector and private shareholders ( $\mathrm{Li}$ and Rozelle 2000; Reza 2007). Furthermore, the general withdrawal of state or public services in certain areas is a form of privatisation since it reduces state responsibilities and increases the reliance on private service providers (Bailey 1987, 139). 
Although privatisation often refers to a dynamic process of change over time, privatisation can also be examined from a comparative perspective, whereby, for instance, the degree of privatisation in a particular region is compared with other regions. In this paper, the term privatisation refers to the proportional size of the private sector when comparing different regions in Western China. This measure is advantageous because it might be less confounded by the degree of economic development.

Privatisation is often associated with greater individual differentiation and overall income inequality (Bandelj and Mahutga 2010). Combined with an increase in private sector, income inequality in China has increased substantially in the economic reform period. Based on data from the UNU-WIDER, the Gini coefficient in China was around .30 in 1980, but had nearly doubled to .55 by 2012 (Xie and Zhou 2014). Further, income inequality in China had far exceeded the average for other countries at a similar level of economic development.

Economic growth has been concentrated in Eastern coastal provinces, while the Western region has been lagging behind. This widening regional gap has become one of the most important aspects of inequality in China (Chow 2007, 178). The Western region covers $74 \%$ of the national territory and $29 \%$ of the national population. Yet, by 2002, Western China accounted for only $17 \%$ of China's total GDP, while the income per capita was $40 \%$ of the value in Eastern areas (Lu and Neilson 2004). The mean income in the East was twice as high as in the West (Gustafsson et al. 2008).

In order to reduce uneven regional development between the East and West, in 2000, the Chinese government launched a campaign to 'open up the West', with an emphasis on developing infrastructure and promoting market economy through the privatisation of state-owned enterprises and increased foreign direct investments (Chow 2007). An important ambition of the campaign was to 'achieve common prosperity' (CCCPC 2000). In addition, the campaign was intended to privatise the state sector in order to achieve higher productivity and efficiency. The development strategy comprises of economic reform, privatisation, promotion of foreign direct investment and sustainable development (Chow 2007).

The campaign may have contributed to decreasing inequality when the Western and Eastern regions are compared at the macro-level (Mao 2011). This is still up for debate. For example, Wu (2007) has found that inequalities between the regions have actually risen in the years after the campaign, both in terms of income and GDP per capita. Furthermore, the processes of modernisation and privatisation might have caused increased inequality within the Western provinces and prefectures, thus creating further stratification and divisions which might lead to decreased political and social stability. Patterns of inequality vary substantially within the Western provinces. Fan and Sun (2008) found that there were relatively stable intraregional inequalities in the 2000s, and similar findings were found within Western China as a whole (Groenewold et al. 2008). But when distinguishing between Northwest and Southwest, it became clear that inequality had developed in different ways; there was a clear fall in the Gini coefficient in the Northwest, but the Gini increased in the Southwest in the same time period (Groenewold, Chen and Lee 2008, 25).

One way to understand the different effects of this reform on inequality is to examine the extent to which different districts within Western China have been privatised. The impact of the stratifying mechanisms implicated in the reforms on income inequality may vary according to the degree of privatisation in the region. 
Local government has played a vital role of regulating labour market and distributing/ redistributing resources in local areas. Prefectures are subdivisions of provinces and are located at the second political and administrative level in China. There is much variation among prefectures when it comes to the organisation and practices of the political and socioeconomic institutions. Comparing the sizes of private sectors across regions may also capture the regional characteristics and structural differences between regional units.

\section{Market transition theory}

The relationship between privatisation and income inequality in Western China can be discussed in light of market transition theory. The theory describes how income determinants are affected when a redistributive economy is replaced by a market economy. Important studies in post-communist countries and in China have raised theoretical and empirical debates about the dynamics of income distribution and inequality in the marketisation process, and their relation to political, economic and institutional mechanisms (Nee 1989; Walder 1996; Xie and Hannum 1996).

Market transition theory has been widely debated with regard to the consequences of economic transitions in former communist societies (Bian and Logan 1996; Nee 1992; Nee 1996; Nee and Cao 2005; Szelenyi and Kostello 1996). The work of Victor Nee has been central to the development of market transition theory in the Chinese context. He proposes that as the market sector grows, market mechanisms will gradually replace political mechanisms when it comes to the distribution of income (Nee 1989; Nee and Cao 2005).

According to market transition theory, employees in the state and public sectors are facing reduced protection and income when economic policy is taken in a more market-oriented direction, while individuals in the private sector may get better wages through the restructured system. Wages in the public sector were previously higher, but can be expected to decrease as the enterprises are privatised and expenses cut (Haskel and Szymanski 1993). Haskel and Szymanski maintain that wage levels between public and private sectors will even out and be at roughly the same level in different enterprises across sectors.

This theory is much debated. Many critiques point out that market transition theory ignores the fact that market and state are highly related. Since market reforms in China are initiated and regulated by the state, market cannot be disentangled from state intervention. Bian and Logan (1996) proposed the persistence of power theory, arguing that institutions such as work units (danweis) and state bureaucracy continue to play an important role in redistributing income. The state is still a strong actor in China and that political power is still dominant in determining individual socioeconomic positions and resources. Institutional arrangements of work organisations were also recognised as having important impact (Lin and Bian 1991; Zhou, Tuma and Moen 1997). Political and institutional circumstances must therefore be taken into account when studying the impact of the market.

Recent empirical studies have also shown evidence that is inconsistent with market transition theory. For example, Fu and colleagues (Fu, Zhu, and Ren 2015) found that employment in the state sector remained important for a household's entitlement to homeownership and subsidised rental housing. They interpreted their findings in light of the power theory, in which political power was producing economic power. Xie and Hauser (2005) found that changes in returns to political capital do not vary with 
marketisation. In contrast, marketisation is associated negatively with the increase in returns to education. Moreover, some argue that there is heterogeneity in returns to the private sector. For example, Wu (2010) observed that people entered the market sectors for different reasons: some self-selected to do so for higher economic returns, but others were pushed into the market through layoffs. He found that only people who entered the market sector voluntarily received higher earnings, and a late market entry was negatively associated with individual income.

The process of marketisation started later in Western areas of China compared to the East, and it was still very much an ongoing process in the early 2000s. It is therefore interesting to see if the market process, measured by the degree of privatisation, has led to changes in income differences. Market transition theory suggests that when income levels increase in the private sector and decrease in the state sector, the overall result will be a decline in overall income inequality. If market transition theory is correct, a higher level of privatisation will correlate with lower income inequality. Our first hypothesis of this paper is:

\section{H1. Privatisation is negatively correlated with income inequality in Western China}

Furthermore, market transition theory indicates that sector differences change the pattern of income inequality because of higher productivity in private enterprises relative to stateowned enterprises, resulting in higher profits in the private sector. Our second hypothesis is:

H2. Income differences between the private and public sectors are reduced with a higher degree of privatisation

According to market transition theory, whereas the hierarchy in the public sector is based on political capital and positions, the dominant income-generating principles in the market sector are human capital, returns to education, and the control of capital and investments. Human capital and rates of return to education have received a great deal of attention in the transition debate, as they are taken to be the central feature of the market sector (Nee 1989). The expansion of the private sector in China's marketoriented reform has led to overall increased rates of return to education, notably in the private sector. This suggests that individual income to a larger extent depends on individual education and that the rates of return to education vary between prefectures with different degrees of privatisation. A related hypothesis is:

\section{$\mathrm{H} 3 \mathrm{a}$. The higher degree of privatisation, the higher income inequality between individuals with different educational attainment}

Furthermore, the control of capital and investments are also important factors. With the growth of the private sector, the principle 'high skills pay-off' in the private sector has been explored (Ho et al. 2002). Occupation-based reward systems have gained increased importance in China's developing market economy, and occupational class significantly impacts individuals' income and economic situation (Bian and Zhang 2002; Nee and Cao 2005; Shue and Wong 2007). Increased demand for skilled workers in a competitive labour market implies increased salaries for skilled workers, and a merit-based reward system in private enterprises also contributes to income differentiation (Nee and Cao 2005). Jobs in the service class are typically located in the well- 
paid, high-skilled primary sector, while working class and agricultural jobs are typically located in the low-paid, low-skilled secondary sector (Piore 1979, 17). According to market transition theory, we may expect that a larger private sector can contribute to increased wage stratification between different occupational classes in Western China:

$\mathrm{H} 3 \mathrm{~b}$. The higher degree of privatisation, the higher income inequality between individuals with different occupational positions

A third factor is the household registration system (hukou system), which has had a significant impact on people's livelihood since its implementation in 1958. The hukou system has remained active throughout the reform period, although the system has been liberalised to some extent (Whyte 2010, 20). In urban areas, social benefits such as healthcare and schooling have been maintained at relatively high levels in the reform period, and there is more state welfare available to residents with urban hukou. One reason for why is more welfare available to residents with urban hukou is that relatively high proportions of urban citizens were employed in the state-owned enterprises from the pre-reform era, and the state sector is generous with social benefits. In rural areas, not many people worked in the state sector, and they became self-supported when services and security disappeared. If the market process decreases the level of material privileges connected to the state sector, as suggested by market transition theory, we may expect that in prefectures with a higher degree of privatisation, people with urban hukou will have fewer income advantages:

$\mathrm{H3c}$. The higher degree of privatisation, the higher income inequality between rural and urban citizens

It is widely recognised that education, occupation and hukou have impacts on income differences in China. For example, $\mathrm{Hu}$ and Hibel (2015) found that returns to higher education in urban China increased in the 2000s and that the return to education varies for people with different income levels. Zhang et al. (2005) showed that returns to education in urban China more than doubled between 1998 and 2001. Gustafsson et al. (2015) found that income inequality has increased rapidly in China, and the association between education and earnings is strong and important. Appleton et al. (2014), however, found that education returns have been equalising in the 2000s, but wage differentials due to gender, occupation, ownership, sector and province have widened. Furthermore, although income for different occupational positions may result in unequal wages, the study found that the effect may vary between different work units (danweis). The largest earning inequality among occupations can be found in state institutions, whereas there is less occupational segregation in private enterprises (Zhang and Wu 2016). Moreover, other factors may also contribute to uneven income distribution. For example, when comparing China and the USA, Xie and Zhou (2014) identified several other predictors of income: region, area type, education, race/ethnicity and family structure.

International studies have also identified other important determinants for income inequality. Such factors include economic growth (Rubin and Segal 2015), urbanisation (Behrens and Robert-Nicoud 2014; Su et al. 2015), ethnic composition (Alesina, Piccolo, and Pinotti 2016; Mather and Jarosz 2014) and family structure (Martin 2006; McLanahan and Percheski 2008). 
Since studies of Western China are rather few, this study explores how these different individual and regional factors are related to income inequality in the context of Western China.

\section{Data and methods}

Data

The dataset used in this paper is Fafo's Monitoring Social and Economic Development of Western China (MEDOW), an extensive survey of living conditions conducted between 2004 and 2005. The MEDOW survey was conducted by the Research Institute Fafo in Norway, in cooperation with the Chinese partners. The survey includes data on population composition, health, household economy, work and employment, education, living conditions, migration, infrastructure and agriculture. A total of 167,000 individuals in 44,738 households participated in the survey, which covers 11 provinces in Western China: Gansu, Xinjiang, Yunnan, Ningxia, Guangxi, Guizhou, Qinghai, Chongqing, Sichuan, Inner Mongolia and Shanxi. The only Western province not included in the survey was Tibet. The provinces in MEDOW covered 5.6 million square kilometres, $58 \%$ of the total geographic area of China.

The data in MEDOW were collected through four questionnaires: a main household questionnaire, an adult female questionnaire, a randomly selected individual questionnaire for household members and a community questionnaire. The household questionnaire contains rich information on the household economy, household infrastructure, housing conditions, agricultural activities and environmental threats as well as information about individuals in the household: their gender, age, hukou registration, marital status, education, employment status, etc. This paper is based on individual survey data and data about household economy from the household questionnaire.

The sampling process in MEDOW was done in several steps. The sampling is stratified by province (the sampling frame) and then implicitly stratified by urban-rural and geographical location, as well as demographic structure. Each of the provinces was divided into 18 replicate sample areas, drawn from 14 primary sampling units based on lists from the neighbourhood committees and townships. The primary sampling units were selected by a probability sampling with inclusion probabilities proportional to the population of each unit. In the 14 primary sampling units, 16 households were chosen (20 households in cities with higher probability with non-response). For description of the sampling method in more detail see documentation from NRCSTD (National Research Center for Science and Technology for Development) and Fafo (2006).

Of totally 44,738 households selected for interviews, there were 41,695 households that were able to participate; and 41,222 households of the selected households completed the interviews. This is a very high participation rate-of the households that were sampled, $94 \%$ were interviewed. Less than $1 \%(.96 \%)$ refused to participate, and the reasons for non-response or incomplete interviews were that the interviewer could not find the household location or that no household members were home or that the interview was interrupted. Some of the absence is because of confused or obviously wrong answers. The sample can therefore be assumed to be representative for households and individuals in Western China. 
In this study, observations are limited to adult with a job, aged 16-65. Since we are interested in examining market transition theory, the employment sector is important for our analysis. We have therefore excluded observations that lack information about work sector. This restriction reduced the sample to 49,873 observations.

\section{Variables}

The degree of privatisation at prefecture level is measured by the percentage of wage earners who are working in the private sector. The primary job sector is the sector in which the respondent mainly works. Private enterprises include three capital enterprises, domestic private firms, foreign investment and household businesses.

Income inequality is measured by Gini coefficients in each prefecture. Individual income is defined as the total annual income earned from all of the respondent's income activities, including both individual and household income sources. The individual income variable is the sum of three MEDOW categories: individual income, agricultural income and family income. Agricultural and family incomes are determined on the basis of total household income and calculated by dividing total household income with the number of household members who participated in agricultural and family business work. Both inequality and income measure are transformed to the natural logarithm.

Sector is based on employment and is divided into state, collective, agriculture, private and organisations. Education is measured as years of education completed. Occupation is grouped into three broad occupational categories: service class, working class and agricultural class. Household registration marks the difference between urbanand rural-registered residences. Sickness is a dummy variable, in which people with acute diseases, chronic diseases, disability or psychological illnesses are defined as sick. BMI is another measure for physical health, where a person with BMI within the range of $18.5-24.9 \mathrm{~kg} / \mathrm{m}^{2}$ is defined as having a normal BMI, and both overweight and underweight $\left(<18.5\right.$ or $\left.\geq 25 \mathrm{~kg} / \mathrm{m}^{2}\right)$ are defined as abnormal.

See Table 1 for descriptive statistics of all variables used in the analysis. Note that in the multilevel analysis, all continuous independent variables were centred to their grand mean. See Additional file 1: Appendix II for more information about the variables.

\section{Methods}

Inspired by macro-micro model of social explanation (Coleman 1994), the analysis was completed in three stages in order to identify links between macro and micro actions. First, we estimated the empirical correlation between privatisation and income inequality at the prefectural level. The unit of analysis is the 128 prefectures. Simple ordinary least squares (OLS) regressions were estimated with prefecture level control variables: percentage Han ethnic majorities living in a prefecture, percentage of people living in urban areas (used as an indicator for urbanisation), average household size, income and education. Since regional heterogeneity in China is also important (Bakkeli 2016; Xie and Hannum 1996), we will control for regional fixed effects in this analysis.

Second, using multilevel analysis, we assessed the micro relationship between individuals' social position (education level, occupation class, employment sector and household registration) and their income. Here, we observe how this relationship varies with different degrees of privatisation in different prefectures. 
Table 1 Descriptive statistics for the original variables used in multilevel analysis. $N=49,873$

\begin{tabular}{|c|c|c|c|c|}
\hline Variables & Mean & SD & Min & Max \\
\hline \multicolumn{5}{|l|}{ Prefecture level } \\
\hline Privatisation & 22.89 & 7.65 & 0 & 45.03 \\
\hline Gini & .55 & .06 & .31 & .66 \\
\hline Log Gini & -.61 & .12 & -1.18 & -.41 \\
\hline Average income & 4292.56 & 1888.40 & 1559.69 & 21653.52 \\
\hline Average education & 5.47 & 1.19 & 1.32 & 1.29 \\
\hline Avrg household size & 4.48 & .61 & 2.86 & 6.60 \\
\hline \% Han Chinese & .69 & .30 & 0 & 1 \\
\hline$\%$ Living in cities & .12 & .14 & 0 & 1 \\
\hline \multicolumn{5}{|l|}{ Individual level } \\
\hline Income & 4273.01 & 7155.84 & 0 & 400000 \\
\hline Log income & 7.68 & 1.37 & 0 & 12.90 \\
\hline Gender & .48 & .50 & 0 & 1 \\
\hline Age & 41.64 & 10.84 & 16 & 65 \\
\hline Majority & .71 & .45 & 0 & 1 \\
\hline Married & .96 & .21 & 0 & 1 \\
\hline Urban hukou & .17 & .38 & 0 & 1 \\
\hline Household size & 4.33 & 1.55 & 1 & 19 \\
\hline Education & 5.35 & 4.25 & 0 & 23 \\
\hline Has been sick & .32 & .47 & 0 & 1 \\
\hline Normal BMI & 22.14 & 2.97 & 9.28 & 75.46 \\
\hline \multicolumn{5}{|l|}{ Occupational class } \\
\hline Working class & .08 & .27 & 0 & 1 \\
\hline Service class & .17 & .37 & 0 & 1 \\
\hline Agriculture & .75 & .43 & 0 & 1 \\
\hline \multicolumn{5}{|l|}{ Sector } \\
\hline Agriculture & .77 & .42 & 0 & 1 \\
\hline State & .11 & .31 & 0 & 1 \\
\hline Collective & .01 & .09 & 0 & 1 \\
\hline Private & .10 & .30 & 0 & 1 \\
\hline Organisations & .01 & .08 & 0 & 1 \\
\hline Other & .01 & .09 & 0 & 1 \\
\hline Working hour & 48.11 & 25.33 & 0 & 168 \\
\hline
\end{tabular}

The empty model (model 1) only contains random groups and random variation within groups and can be expressed as

$$
Y_{i j}=\gamma_{00}+U_{0 j}+R_{i j}
$$

The dependent variable is the natural logarithm of income for individual $i$ in prefecture $j$, given by $Y_{i j}$. $\gamma_{00}$ is a general mean, $U_{0 j}$ is the random effect at the group level and $R_{i j}$ is the random effect at the individual level. Model 2 and model 3 estimate random intercept effects. The level 2 equation includes five variables, $x_{1 i j}$ to $x_{5 i j}$ (education, working class, service class, private sector and household registration) that explain the random effects. Variables without random slopes are denoted as $z_{i j i}$. Any $W_{*_{j}}$ are level 2 variables. A 
linear relationship for the random intercept model with cross-level interaction terms can be expressed with this equation (2):

$$
Y_{i j}=\left(\gamma_{00}+\sum_{h=1}^{p} \gamma_{h 0} x_{h i j}+\sum_{k=1}^{q} \gamma_{0 k} W_{k j}+\sum_{l=1}^{r} \zeta_{l j} z_{l i j}\right)+\left(U_{0 j}+R_{i j}\right)
$$

where $p, r$ and $q$ represent the number of level 1 variables with random slopes, the number of level 1 variables without random slopes and the number of level 2 explanatory variables, respectively.

Model 4 estimates random slope. The equation for the random effect model can be written as:

$$
\begin{aligned}
Y_{i j}= & \left(\gamma_{00}+\gamma_{01} W_{j}+\sum_{h=1}^{p} \gamma_{h 0} x_{h i j}+\sum_{k=1}^{q} \gamma_{0 k} W_{k j}+\sum_{k=1}^{q} \sum_{h=1}^{p} \gamma_{h k} W_{k j} x_{h i j}+\sum_{l=1}^{r} \zeta_{l j} z_{l i j}\right) \\
& +\left(U_{0 j}+\sum_{h=1}^{p} U_{h j} x_{h i j}+R_{i j}\right)
\end{aligned}
$$

where $\gamma$ and $\zeta$ are fixed coefficients. $U_{0 j}$ and $U_{h j}$ are random variables with the standard properties, representing the group-specific part of the intercept and coefficient, respectively. In this study, the cross-level interactions are restricted by explaining each random coefficient using only one level 2 variable, privatisation. Equation (3) represents the combined effect of the macro-cause of privatisation and micro-factors of individual position and income. The macro relation can also be embedded into this equation because it gives the mean level of $y$ in group $j$.

Finally, the link between micro-level individual income and macro-level income inequality is then a matter of aggregation of income within prefectures. In a simulation experiment, we examine what income inequality would look like given the results of the individual-level analysis, by using the parameters estimated in stage two to simulate the aggregate income inequality at the prefecture level under varying privatisation regimes.

\section{Results}

\section{Stage 1. Macro relationship}

The bivariate correlation between privatisation and income inequality at the prefecture level is shown in Table 2. All predictors are standardised in these two models in order to make the variables comparable. When predicting log Gini with prefecture-level predictors, two models are used. Model I-1 is an OLS regression with six prefecture-level variables, whereas model I-2 includes province fixed effects.

The regression coefficient for privatisation was estimated to be .05 in models I-1 and I-2, i.e. increment in privatisation by one standard deviation corresponds to an increase in the Gini coefficient by about $5 \%$. The coefficient is significantly different from zero at the $1 \%$ level. This rejects the first hypothesis (H1), showing that a higher degree of privatisation is not associated with lower levels of inequality as market transition theory indicates. We find instead that privatisation contributes to increasing income differences.

It is worth noting that when controlling for regional heterogeneities by including province dummies, a higher degree of privatisation is still correlated with greater 
Table 2 OLS estimates for log Gini, full model

\begin{tabular}{|c|c|c|}
\hline & Model I-1 & Model I-2 \\
\hline (Standardised predictors) & Coefficient (S.E.) & Coefficient (S.E.) \\
\hline Privatisation & $.050(.013)^{* * *}$ & $.047(.015)^{* *}$ \\
\hline$\%$ Han Chinese & $-.004(.012)$ & $.006(.014)$ \\
\hline Average household size & $.016(.018)$ & $-.010(.021)$ \\
\hline$\%$ Living in cities & $-.031(.018)^{\dagger}$ & $-.033(.017)^{\dagger}$ \\
\hline Average income & $-.012(.018)$ & $-.037(.016)$ \\
\hline Average years of education & $-.013(.022)$ & $.004(.022)$ \\
\hline \multicolumn{3}{|l|}{ Provinces (Gansu) } \\
\hline Guangxi & & $.019(.047)$ \\
\hline Guizhou & & $.005(.044)$ \\
\hline Inner Mongolia & & $-.091(.062)$ \\
\hline Ningxia & & $.094(.044)^{*}$ \\
\hline Qinghai & & $.251(.050)^{* * *}$ \\
\hline Shaanxi & & $-.034(.041)$ \\
\hline Sichuan & & $-.045(.050)$ \\
\hline Xinjiang & & $.033(.050)$ \\
\hline Yunnan & & $-.044(.041)$ \\
\hline Chongqing & & $.107(.044) *$ \\
\hline Constant & $-.644(.011)^{* * *}$ & $-.645(.030)^{* * *}$ \\
\hline R-squared & .34 & .54 \\
\hline N & 128 & 128 \\
\hline
\end{tabular}

Notes: ${ }^{* * *} p<.001 ;{ }^{* *} p<.01 ;{ }^{*} p<.05 ;{ }^{\dagger} p<.10$

income inequality, but province differences do not have much influence on income inequality. Exploring lower regional divisions below province levels is therefore relevant in the following analysis.

\section{Stage 2. Multilevel analysis}

The second stage of the analysis involves assessing how education and occupation affect the income of individuals located in prefectures with different degrees of privatisation. The multilevel analysis is shown in Table 3. In all of our models, all continuous independent variables are grand-mean centred, and standard errors are clustered at prefecture level. The variables are not standardised, in order to make the interpretation more straight forward.

Model 1 is an empty model with only a random intercept. The average log income across prefectures is 7.35 , which gives an average income of $e^{7.75}=2322$ yuan. The intraclass correlation coefficient (ICC) is .136, meaning that $13.6 \%$ of the total variance in log income is attributable to the prefecture level.

Models 2 through 4 are full models using maximum likelihood estimations (MLE) with unstructured covariance structure. Model 2 estimates a random intercept effect. The random intercept model allows intercepts to vary between different prefectures, but the slope stays the same. This provides an initial indication of the extent to which unobserved prefecture-level characteristics contribute to variations in income inequality, acting as a baseline comparison for subsequent models. 
Table 3 Multilevel regression coefficients for individual and aggregated factors on log income

\begin{tabular}{|c|c|c|c|c|}
\hline \multirow[t]{2}{*}{ Fixed effects } & Model 1 & Model 2 & Model 3 & Model 4 \\
\hline & Coefficient (S.E.) & Coefficient (S.E.) & Coefficient (S.E.) & Coefficient (S.E.) \\
\hline \multicolumn{5}{|l|}{ Individual variables } \\
\hline Men & & $.190(.013)^{* * *}$ & $.189(.013)^{* * *}$ & $.188(.013)^{* * *}$ \\
\hline Age & & $.003(.001)^{* * *}$ & $.004(.001)^{* * *}$ & $.003(.001)^{* * *}$ \\
\hline Age squared & & $-.001(.000)^{* * *}$ & $-.001(.000)^{* * *}$ & $-.001(.000)^{* * *}$ \\
\hline Majority & & $.048(.034)$ & $.056(.033)^{\dagger}$ & $.063(.033)^{\dagger}$ \\
\hline Married & & $.126(.033)^{* * *}$ & $.127(.033)^{* * *}$ & $.125(.033)^{* * *}$ \\
\hline Urban hukou & & $.227(.038)^{* * *}$ & $.220(.041)^{* * *}$ & $.238(.049)^{* * *}$ \\
\hline Household size & & $-.048(.007)^{* * *}$ & $-.048(.007)^{* * *}$ & $-.046(.008)^{* * *}$ \\
\hline Education & & $.042(.002)^{* * *}$ & $.041(.002)^{* * *}$ & $.038(.003)^{* * *}$ \\
\hline Has been sick & & $-.123(.016)^{* * *}$ & $-.120(.015)^{* * *}$ & $-.114(.015)^{* * *}$ \\
\hline Normal BMI & & $.003(.013)$ & $.002(.013)$ & $.001(.013)$ \\
\hline \multicolumn{5}{|l|}{ Occupation (ref. agriculture) } \\
\hline Working class & & $.106(.059)^{\dagger}$ & $.097(.057)^{\dagger}$ & $.041(.055)$ \\
\hline Service class & & $.507(.073)^{* * *}$ & $.508(.073)^{* * *}$ & $.424(.064)^{* * *}$ \\
\hline \multicolumn{5}{|l|}{ Sector (ref. state) } \\
\hline Agriculture & & $-.650(.079)^{* * *}$ & $-.646(.080)^{* * *}$ & $-.690(.069)^{* * *}$ \\
\hline Collective & & $-.327(.093)^{* *}$ & $-.330(.092)^{* *}$ & $-.358(.093)^{* *}$ \\
\hline Private & & $-.357(.052)^{* * *}$ & $-.393(.052)^{* * *}$ & $-.424(.053)^{* * *}$ \\
\hline Organisation & & $-.791(.102)^{* * *}$ & $-.791(.123)^{* * *}$ & $-.805(.109)^{* * *}$ \\
\hline Others & & $-.956(.123)^{* * *}$ & $-.951(.124)^{* * *}$ & $-1.028(.124)^{* * *}$ \\
\hline Working hour & & $.002(.000)^{* * *}$ & $.002(.000)^{* * *}$ & $.003(.000)^{* * *}$ \\
\hline \multicolumn{5}{|l|}{ Prefecture variables } \\
\hline Privatisation & & $-.006(.003)^{\dagger}$ & $-.011(.004)^{* *}$ & $-.014(.003)^{* * *}$ \\
\hline Average pref. income & & $.072(.027)^{*}$ & $.085(.026)^{* *}$ & $.062(.016)^{* *}$ \\
\hline Average pref. education & & $-.010(.026)$ & $-.001(.025)$ & $-.002(.020)$ \\
\hline \% Han Chinese & & $-.264(.099)^{* *}$ & $-.230(.095)^{*}$ & $-.148(.070)^{*}$ \\
\hline Average household size & & $-.111(.046)^{*}$ & $-.093(.045)^{*}$ & $-.085(.031)^{* *}$ \\
\hline$\%$ Living in cities & & $-.129(.267)$ & $-.256(.246)$ & $-.030(.168)$ \\
\hline \multicolumn{5}{|l|}{ Cross-level interaction } \\
\hline Education $\times$ privatisation & & & $.000(.000)$ & $.000(.000)$ \\
\hline Working class $\times$ privatisation & & & $.010(.006)$ & $.011(.006)^{\dagger}$ \\
\hline Service class $\times$ privatisation & & & $.005(.007)$ & $.009(.007)$ \\
\hline Private sector $\times$ privatisation & & & $.010(.005)^{\dagger}$ & $.008(.005)$ \\
\hline Hukou $\times$ privatisation & & & $-.005(.005)$ & $-.001(.006)$ \\
\hline Intercept & $7.751(.046)^{* * *}$ & $8.232(.097)^{* * *}$ & $8.223(.099)^{* * *}$ & $8.290(.091)^{* * *}$ \\
\hline Random effects & \multicolumn{4}{|c|}{ Variance component } \\
\hline$\sigma_{u}$ & $.516(.034)^{* * *}$ & $.221(.020)^{* * *}$ & $.215(.020)^{* * * *}$ & $.858(.019)^{* * *}$ \\
\hline$\sigma_{e}$ & $1.298(.004)^{* * *}$ & $1.166(.025)^{* * *}$ & $1.165(.026)^{* * *}$ & $1.150(.025)^{* * *}$ \\
\hline$\sigma_{\text {education }}$ & & & & $.018(.003)^{* * *}$ \\
\hline$\sigma_{\text {working class }}$ & & & & $.423(.045)^{* * *}$ \\
\hline$\sigma_{\text {service class }}$ & & & & $.382(.054)^{* * *}$ \\
\hline$\sigma_{\text {private sector }}$ & & & & $.395(.062)^{* * *}$ \\
\hline$\sigma_{\text {hukou }}$ & & & & $.421(.090)^{* * *}$ \\
\hline$\sigma_{\text {intercept }}$ & & & & $.279(.027)^{* * * *}$ \\
\hline
\end{tabular}


Table 3 Multilevel regression coefficients for individual and aggregated factors on log income (Continued)

\begin{tabular}{|c|c|c|c|c|}
\hline \multicolumn{5}{|c|}{ Correlation with the random intercept } \\
\hline \multicolumn{4}{|l|}{ Education } & $.051(.164)$ \\
\hline \multicolumn{4}{|l|}{ Working class } & $-.539(.085)^{* * *}$ \\
\hline \multicolumn{4}{|l|}{ Service class } & $-.583(.104)^{* * *}$ \\
\hline \multicolumn{4}{|l|}{ Private sector } & $-.034(.169)$ \\
\hline \multicolumn{4}{|l|}{ Hukou } & $-.304(.131)^{* * *}$ \\
\hline \multicolumn{5}{|l|}{ Model fits } \\
\hline ICC & .136 & .035 & .033 & .358 \\
\hline Log likelihood & -84011.38 & -78577.15 & -78525.45 & -78120.29 \\
\hline $2 \mathrm{LL}$ & 168022.76 & 157154.3 & 157050.3 & 156240.58 \\
\hline \multicolumn{2}{|l|}{ 2LL change } & 10868.46 & -104 & 809.72 \\
\hline \multicolumn{2}{|c|}{ Snijders/Bosker R2 (level 1/2) } & $.278 / .793$ & $.281 / .803$ & $.281 / .803$ \\
\hline AIC & 168028.8 & 157208.3 & 157114.9 & 156344.6 \\
\hline$N$ (obs.) & 49873 & 49873 & 49873 & 49873 \\
\hline$N$ (groups) & 128 & 128 & 128 & 128 \\
\hline
\end{tabular}

Notes: ${ }^{* * *} p<.001 ;{ }^{* *} p<.01 ;{ }^{*} p<.05 ;{ }^{\dagger} p<.01$

In this model, privatisation appears to have a negative effect on individual income, but the effect is not significant at $p<.05$. The average income in a prefecture is positively correlated to individual income, but the effect size is minimal. Furthermore, individual income decreases with a higher percentage of Han ethnic Chinese (the majority) living in the prefecture. It also decreases if the household structure is larger in the prefecture.

Individual characteristics are important for income. Higher income is correlated with being male, older, married, not being sick in the last month or having chronic diseases, and living in a smaller household. Each additional year of education gives a $4.2 \%$ increase in income. People with urban registration on average have $23 \%$ higher income. When considering occupational class, working class does not differ significantly from agricultural workers at $p<.05$, but service class has an income $51 \%$ higher than agricultural workers. Moreover, income levels in all other sectors are significantly lower compared to those who work in the state sector.

Cross-level interaction terms were added in model 3. None of the interactions are significant at the $5 \%$ level, however, meaning that correlations between privatisation and the chosen variables (education, occupation, sector and household registration) do not vary with the degree of privatisation. This model has a better fit than the previous one, and the parameters for individual variables show similar trends to model 2 . The only difference is that income inequality appears to be significant at $1 \%$. The effect size of privatisation on income has increased as well; when privatisation increases by $1 \%$, income decreases by $1.1 \%$.

Model 4 estimates a random coefficient effect. Elaborating on model 3, model 4 allows the regression slopes of education, occupation, sector and household registration to vary across prefectures. The effect of privatisation is significant at $5 \%$ and has increased compared to model 3. Each 1\% increase in degree of privatisation corresponds, on average, to a $1.4 \%$ decrease in individual income in a prefecture. The effect of having a working class occupation is still insignificant, meaning that income for working class and agricultural 
workers are not much different. Higher education, service class occupation, an urban hukou and working in the state sector results in a higher income for an individual.

The cross-level interaction terms show that interaction between privatisation and private sector is not significant. This leads to a rejection of the second hypothesis (H2): income differences between the private and public sectors do not vary with the degree of privatisation. None of the other interaction terms are significant either, and this is relevant for evaluation of hypotheses $H 3 a, H 3 b$ and $H 3 c$. Education, service class occupation and hukou do have an important impact on individual income, but income differences due to these factors do not vary with privatisation.

These findings appear to contradict the market transition hypothesis. Western China was in a starting phase of market process in 2004-2005, but a larger market sector does not correspond to lower income inequality, as indicated by market transition theory. Neither return to education and occupation (high skills pay-off) nor lower urbanrural differences (reduction of state power) could be found in our analysis.

More interesting findings can be seen in the random component. The random components measure the degree to which the random slopes and random intercept vary across prefectures. All random effect terms are significantly different from zero, indicating unexplained variations in income at both individual and prefectural levels, and the effects of individual variables vary significantly across prefectures. Coefficients in variance component indicate the average effect of these individual level characteristics across the prefectures in the data. The standard deviation for education (.018) suggests relatively small variations in education across prefectures. The standard deviations for all other variables are rather high, meaning that there are large prefectural variations in occupation, household registration and employment in the private sector.

Moreover, the standard deviation of the intercept across prefectures is significantly high (.28), which justifies the relevance of a random coefficient model. The correlations between the random intercepts and random slopes of occupation and household registration are significantly negative. This means that prefectures with a higher intercept (higher mean scores on log income) tend to have a flatter slope of occupation and household registration on income. In other words, the effects of occupation and household registration on income are higher when the prefecture has a generally lower level of income.

Note that the error variance increases in this model compared to the empty model. This is because when extra variables are added, the variances are confounded, i.e. changes in variance of the residuals at one level induce changes in variance of residuals at another level (Kreft and de Leeuw 1998).

\section{Stage 3. Simulation}

The final stage of the analysis is to simulate from individual income to aggregated Gini coefficients based on the multilevel models. The simulation is used to test whether a datagenerated income inequality, predicted by income determinants, is able to capture the pattern of actual income inequality distribution in the 128 prefectures in Western China.

Using the likelihood-ratio test to compare models, the result indicates that the random slope model (model 4) is significantly better than the other models. The intraclass correlation in the random slope model is equal to .36 , indicating that $36 \%$ of the total variance is attributed at the prefecture level, which is significantly high. The explained variances at level 1 and level 2 are 28 and $80 \%$, respectively, which is adequately high. 
A quick check of the residuals for model fit shows that residuals from a fitted mode approximate the random errors and the distribution does not deviate from normality (Fig. 1, top left). This suggests that the model fits the data well.

New Gini coefficients are calculated for each of the 128 prefectures, based on the predicted individual income variables from our best models (models 3 and 4). The graph in the top right of Fig. 1 shows the correlation between the original and simulated Gini. The original Gini is clearly more strongly correlated with the Gini estimated by the random slope model (solid line) than with the random intercept model (dashed line).

The linear association between the predicted and the original Gini is strong and positive. This suggests the random slope model is a better predictive and fitted model and can better capture variations in regional diversity and the dispersion of Gini coefficients. Furthermore, when looking at the correlation between the original and estimated Gini coefficients, both Spearman's rank-coefficient and Pearson's correlation coefficient are stronger for the random slope model than for all other models, with respective values of .69 and .68 . This means that the rank of Gini estimated by the random slope model covariate with the rank of actual Gini, indicating an increasing monotonic trend between the two variables.

When taking prefectural varieties into account, we are allowing slopes for individual factors to vary between prefectures. The mean of the Gini estimated from the random slope model is therefore lower than the models with fixed individual effects across prefectures, resulting in lower income inequality. The confidence intervals do not overlap completely with the original interval, meaning that other factors than privatisation may affect income inequality in important ways. However, we can observe that the simulated distribution of

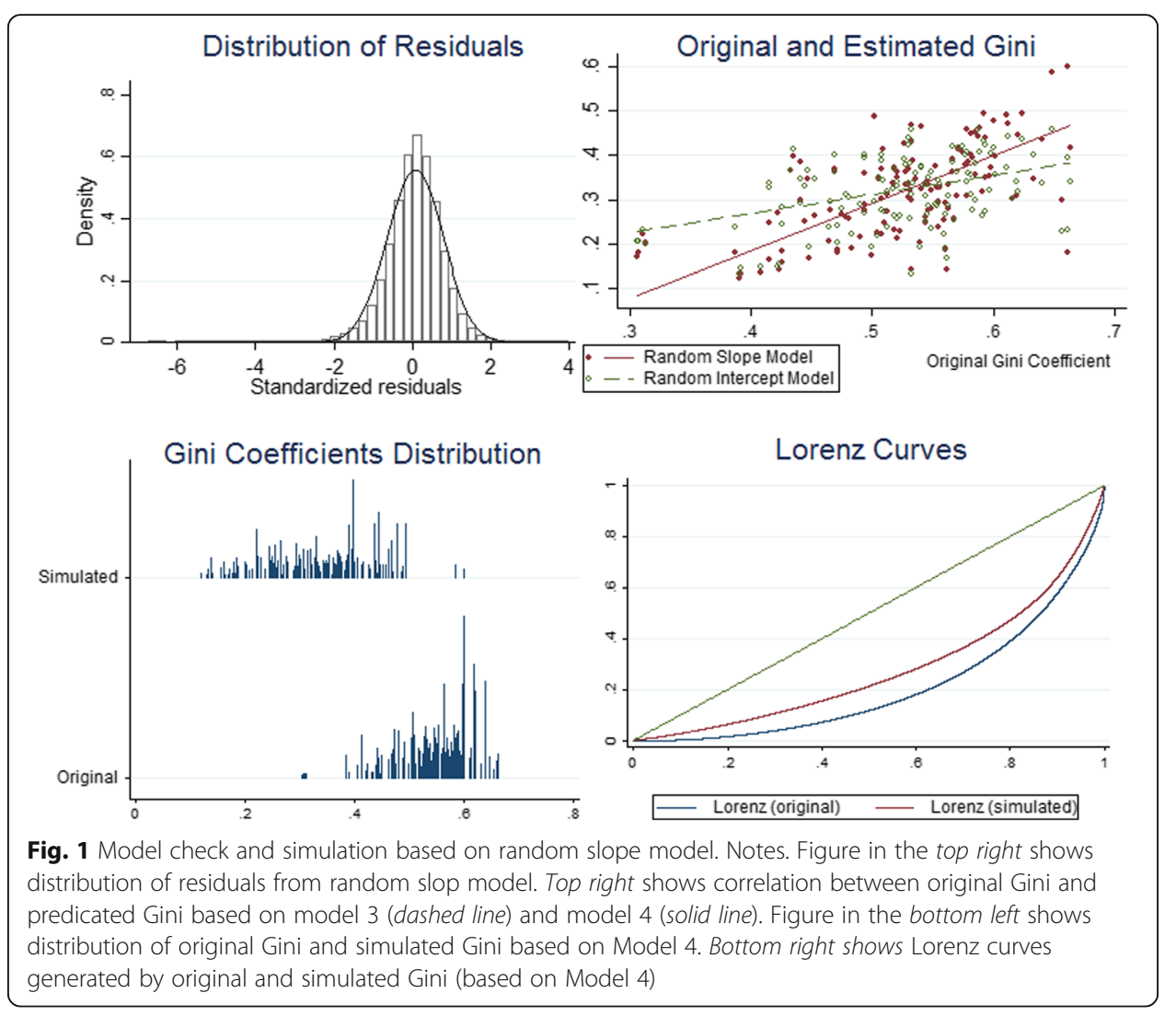


Gini-coefficients in the 128 prefectures predicted by the random slope model is similar to the original distribution (Fig. 1, bottom left).

Finally, a quick check was constructed to examine the relationship between simulated Gini and the level of privatisation. OLS regressions were conducted with all prefecture predictors on the estimated Gini from the random slope model. The regression coefficient is positive and significant. Although income inequality is only predicted by some selected key variables, a higher level of privatisation is still significantly associated with greater income inequality (Fig. 2).

\section{Discussion and conclusions}

In this paper, we have studied the relation between privatisation and income inequality. The analyses have indicated a positive relation between privatisation and income inequality at the macro level and identified education, occupational class, employment sector and household registration status as important factors for individual income distribution at the micro level. Having a higher education, an occupation in the service class, a state sector employment and an urban household registration status positively affects an individual's income level. Furthermore, the effects of education, occupation, employment in the private sector and hukou on individual income do not vary with different degrees of privatisation. The coefficient based on simulated analysis suggested that the aggregated macro income inequality, generated by modelling micro individual income, was still significantly correlated with privatisation. In other words, privatisation, through its effect on different individual and prefectural factors, has a significant impact on income inequality. It also confirms the importance of regional variety in Western China: the Gini coefficient variation is better captured when regional diversity is taken into account.

Three discussions related to market transition theory are relevant. First, market transition theory predicts that the reduction of state privilege combined with increasing market power may reduce inequality. Furthermore, according to the theory, income differences between state and private employees may reduce when the market mechanism

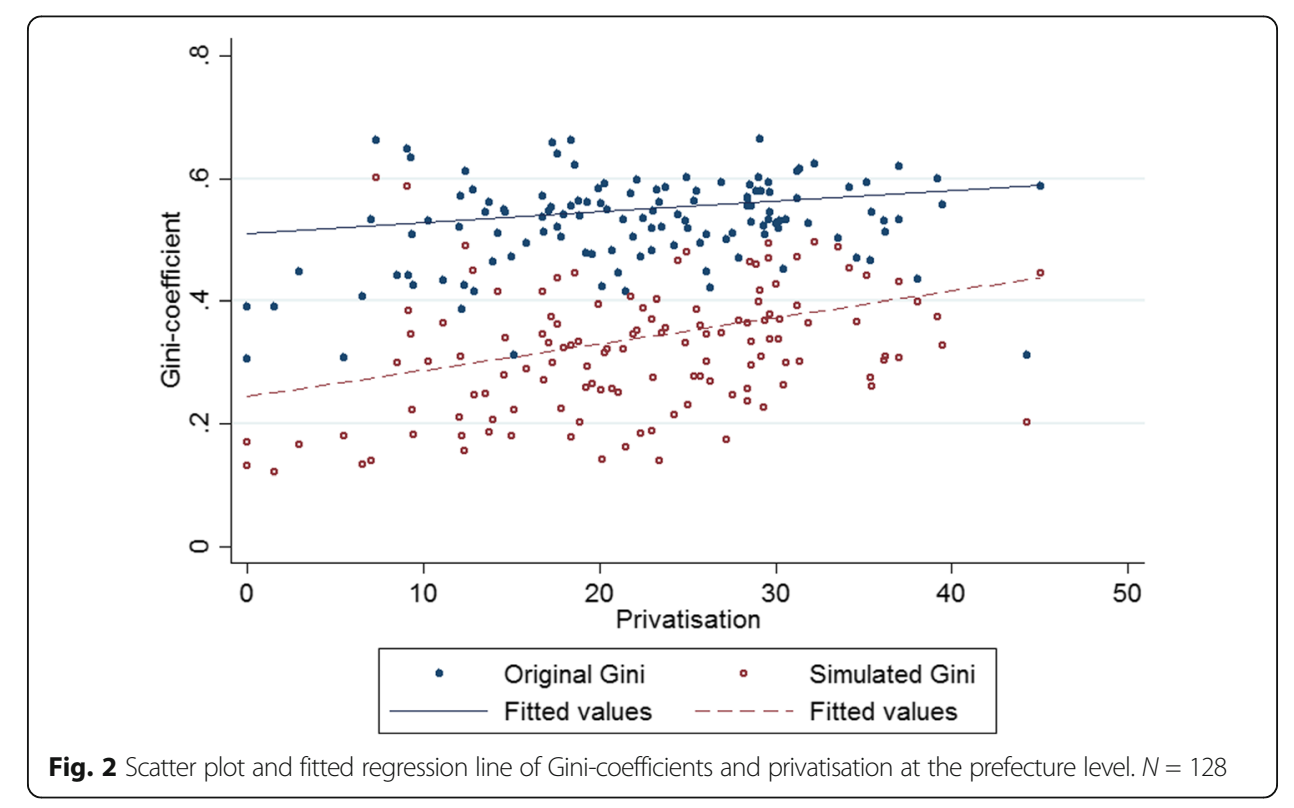


is more dominant. We found, however, that when there is a higher degree of privatisation, it is more difficult to achieve income equality, even in the starting phase of market transition. Income for people working in the state sector is higher than for private employees, independent of the size of private sector. This contradicts market transition theory.

Second, in the market transition theory, demand for higher education and skill-based labour in private sectors was central. Having a highly educated workforce and higher occupational position is equated with high productivity. In a merit-based market economy where productivity is highly valued, people with a higher credential are more likely to be rewarded. Prefectures that are more oriented towards a market economy can be measured by their degree of privatisation. The expectation is therefore that the more privatised the economy, the more rewards go to people who are highly educated. Similarly, the more highly skilled service class would receive higher rewards in prefectures that have transitioned further towards a market economy, indicated by the degree of privatisation.

In our analysis, education and occupation do have an important impact on people's earnings, but these effects remain stable throughout different degrees of privatisation. The effects of education, occupation, sector and hukou do, however, vary between different prefectures. These differences can be caused more by uneven economic development and regional heterogeneity than by market processes themselves. This is also consistent with earlier studies. For example, a study conducted by Xie and Hannum (1996), which tested market transition theory in large cities in China, showed that returns to education are higher in slow-developing cities than in fast-developing cities.

Third, the study confirms the lack of equality between people with urban status and those with rural status, which has been revealed in previous research. However, the relation between household registration and income does not vary significantly with the degree of privatisation. This also contradicts the logic of market transition theory. Privileges for people with urban hukou are often connected to the large proportion of state employees and their advantages in income and welfare benefits. If market transition theory is correct, the reduction of state privilege may lead to reduced inequality between urban and rural hukou holders. We found that income differences between urban and rural hukou holders do not decrease in a prefecture where the private sector is more expanded.

Inequality based on political power and political stratification may be reduced as Chinese society transforms from state socialism to a market economy; when market logic is gaining importance over political mechanisms in distributing wealth and producing income inequality (Sun 2008). In other words, the income inequality between state and private sectors may initially decline before rising again in later phases. It is difficult to determine the turning point or to conclude that Western China had not already passed that point in 2004-2005. Moreover, there might be potential lagging effects of privatisation on inequality. However, it is beyond the scope of this paper to test this hypothesis since changes in inequality over time cannot be observed in cross-sectional data. This could be better explored with longitudinal data and by analysing development over time.

The conclusion drawn from this analysis is that higher income inequality correlates with a higher degree of privatisation in Western China. Privatisation and market process may not be the only reason for income differences, however, and socioeconomic factors such as education and occupation may explain inequality through mechanisms other than the market mechanism. For example, social background and social origin, such as parents' education, are associated with an individual's higher educational performance (Hu and Hibel 
2014). Income inequality may further occur through higher economic returns to high educational attainment, which have been increasing in China. Social and cultural capital may therefore also play an important role in explaining social stratification and income differences. This is also confirmed by other previous studies. For example, using within twin fixed effects, Li et al. (2012) showed that returns to education in urban China are largely due to individual ability or a better family background. There may also be a close link between culture capital, social capital and income. Obukhova (2012) found that social capital is an important income determinant. Among Chinese people with university degrees, those who have stronger social ties also have more advantages in the job market. Research on income inequality, family background and culture capital certainly merit future research.

Privatisation has affected income inequality in Western China. Fundamental institutional changes have occurred with the state withdrawing welfare support and job provision for workers. The rise of the private sector and private ownership has also restructured the Chinese labour market, increasing socioeconomic inequalities. However, state institutions remain important. On average, wages are higher in the state sector than in the private sector. The wage structure is strongly influenced by state institutions established during the planned economy period.

Western China's Development Strategy was basically intended to reduce regional disparities. However, there were contradictions in terms of the policies involved and the way they were implemented. A main contradiction is between the state-owned and privatised enterprises. On the one hand, much effort was put into improving state infrastructure. On the other hand, privatisation was also a central component. The state-owned enterprises in the Western region account for a larger share of the local economy, compared to the coastal region. Privatisation might be used as a complementary tactic to improve the efficiency of state enterprises. But privatisation may also bring about other changes in the labour market. For example, growth in the service sector is usually accompanied with an increase in lowincome and unsecure jobs (Schucher and Hebel 2006). That may be one of the reasons why the average income is lower in prefectures with higher levels of privatisation.

If privatisation lowers average income and increases income inequality, this counters the goal of raising the overall wealth level, in order to catch up with the coastal region. This factor might create lasting tensions between development goals and outcomes. This also concerns the general debate surrounding development and what direction transitional China has taken. Although the adverse effects of rising inequality have gained considerably more attention in recent years, the main focus has still been on economic development, including measures of privatisation. The strategies used in the development of Western China are very similar to those used in Eastern China. The one-sided focus on economic development in the East has not only led to increased inequality between households and uneven development between urban and rural areas, the privatisation of state enterprises and rural collectives has also weakened and even removed public responsibilities for providing welfare services. Although average wage level has risen and national economy has boosted, the cost of development seriously affects individuals' welfare and social security.

\section{Additional file}

Additional file 1: Appendix I. The MEDOW survey data. Appendix II. Description of the variables. Appendix III. Multilevel regression coefficients for individual and aggregated factors on log income for 800 counties. (PDF $446 \mathrm{~kb})$ 
Received: 16 November 2016 Accepted: 21 April 2017

Published online: 11 May 2017

\section{References}

Alesina, Alberto, Salvatore Piccolo, and Paolo Pinotti. 2016. Ethnic Inequality'. J Polit Econ 124(2): 428-88.

Appleton, Simon, Lina Song, and Qingjie Xia. 2014. Understanding Urban Wage Inequality in China 1988-2008: Evidence from Quantile Analysis. World Dev 62(October): 1-13. doi:10.1016/j.worlddev.2014.04.005.

Bailey, Robert W. 1987. Uses and Misuses of Privatization. Proc Acad Polit Sci 36(3): 138-52. doi:10.2307/1174104.

Bakkeli, Nan Zou. 2016. Income Inequality and Health in China: A Panel Data Analysis. Soc Sci Med 157(May): 39-47. doi:10.1016/j.socscimed.2016.03.041.

Bandelj, Nina, and Matthew C. Mahutga. 2010. How Socio-Economic Change Shapes Income Inequality in Post-Socialist Europe. Soc Forces 88(5): 2133-61. doi:10.1353/sof.2010.0042.

Behrens, Kristian, and Frédéric Robert-Nicoud. 2014. Survival of the Fittest in Cities: Urbanisation and Inequality. Econ J 124(581): 1371-1400. doi:10.1111/ecoj.12099.

Bian, Yanjie, and John R. Logan. 1996. Market Transition and the Persistence of Power: The Changing Stratification System in Urban China. Am Sociol Rev 61 (5): 739-58. doi:10.2307/2096451.

Bian, Yanjie, and Zhanxin Zhang. 2002. Marketization and Income Distribution in Urban China, 1988 and 1995. Res Soc Stratification and Mobility 19: 377-415. doi:10.1016/50276-5624(02)80047-6.

CCCPC, (Central Committee of the Communist Party of China State Council). 2000. CPC's Suggestion for the Tenth FiveYear Plans of National Economic and Social Development Stratify (中共中央关于制定国民经济和社会发展第十 个五年计划的建议). News of the Communist Party of China. October 11. http://cpc.people.com.cn/GB/64162/ 71380/71382/71386/4837946.html.

Chow, Gregory C. 2007. China's Economic Transformation. UK: Wiley

Coleman, James S. 1994. Foundations of Social Theory. Cambridge: Harvard University Press

Fan, C. Cindy, and Mingjie Sun. 2008. Regional Inequality in China, 1978-2006. Eurasian Geogr Econ 49(1): 1-18. doi:10.2747/1539-7216.49.1.1.

Fu, Qiang, Yushu Zhu, and Qiang Ren. 2015. The Downside of Marketization: A Multilevel Analysis of Housing Tenure and Types in Reform-Era Urban China. Soc Sci Res 49(January): 126-40. doi:10.1016/j.ssresearch.2014.07.001.

Groenewold, Nicolaas, Anping Chen, and Guoping Lee. 2008. China's Regions and Regional Disparities, 1953 to 2005. In In Linkages between China's Regions: Measurement and Policy. UK: Edward Elgar Publishing Limited.

Gustafsson, Björn A., Li Shi, Terry Sicular, and Yue Ximing. 2008. Income Inequality and Spatial Differences in China, 1988, 1995, and 2002. In Inequality and Public Policy in China, edited by Björn A. Gustafsson, Li Shi, and Terry Sicular. Cambridge: Cambridge University Press.

Gustafsson, Björn, Shi Li, Ludmila Nivorozhkina, and Haiyuan Wan. 2015. Yuan and Roubles: Comparing Wage Determination in Urban China and Russia at the Beginning of the New Millennium. China Econ Rev 35(September): 248-65. doi:10.1016/j.chieco.2014.06.004.

Haskel, Jonathan, and Stefan Szymanski. 1993. Privatization, Liberalization, Wages and Employment: Theory and Evidence for the UK. Economica 60(238): 161-81. doi:10.2307/2554587.

Hauser, Seth M., and Xie Yu. 2005. Temporal and Regional Variation in Earnings Inequality: Urban China in Transition between 1988 and 1995. Soc Sci Res 34(1): 44-79. doi:10.1016/j.ssresearch.2003.12.002.

Ho, Samuel P.S., Xiao-Yuan Dong, Paul Bowles, and Fiona MacPhail. 2002. Privatization and Enterprise Wage Structures during Transition: Evidence from Rural Industry in China. Econ Transit 10(3): 659-88.

Hu, Anning, and Jacob Hibel. 2014. Changes in College Attainment and the Economic Returns to a College Degree in Urban China, 2003-2010: Implications for Social Equality. Soc Sci Res 44(March): 173-86. doi:10.1016/j.ssresearch.2013.12.001.

$\mathrm{Hu}$, Anning, and Jacob Hibel. 2015. Increasing Heterogeneity in the Economic Returns to Higher Education in Urban China. Soc Sci J 52(3): 322-30. doi:10.1016/j.soscij.2013.09.002.

Jefferson, Gary H., and Su Jian. 2006. Privatization and Restructuring in China: Evidence from Shareholding Ownership, 1995-2001. J Comp Econ 34(1): 146-66. doi:10.1016/j.jce.2005.11.008.

Kreft, Ita G. G., and Jan de Leeuw. 1998. Introducing Multilevel Modeling. 1 edition. London; Thousand Oaks, Calif: SAGE Publications Ltd.

Li, Hongbin, Pak Wai Liu, and Junsen Zhang. 2012. Estimating Returns to Education Using Twins in Urban China. J Dev Econ 97(2): 494-504. doi:10.1016/j.jdeveco.2011.05.009.

Li, Hongbin, and Scott Rozelle. 2000. Saving or Stripping Rural Industry: An Analysis of Privatization and Efficiency in China. Agric Econ 23(3): 241-52. doi:10.1016/50169-5150(00)00086-4.

Lin, Nan, and Yanjie Bian. 1991. Getting Ahead in Urban China. Am J Sociol 97(3): 657-88.

Lu, Ding, and William Neilson. 2004. Introduction: West China Development-Issues and Challenges. In China's West Region Development, by Ding Lu and William A W Neilson, 1-14. Londong: World Scientific.

Mao, Qilin. 2011. Can Western Development Program Help to Reduce Income Inequality in China's Western Region_-An Empirical Study Based on the Difference in Difference Model (西部大开发有助于缩小西部地区的 收入不平等吗——基于双倍差分法的经验研究)'. Finance Econ 9: 94-103.

Martin, Molly A. 2006. Family Structure and Income Inequality in Families with Children, 1976 to 2000. Demography 43(3): 421-45.

Mather, Mark, and Beth Jarosz. 2014. The Demography of Inequality in the United States. Population Bulletin 69 (2):1-16.

McLanahan, Sara, and Christine Percheski. 2008. Family Structure and the Reproduction of Inequalities. Ann Rev Sociol 34(1): 257-76. doi:10.1146/annurev.soc.34.040507.134549.

Mok, Ka Ho. 2012. Bringing the State Back In: Restoring the Role of the State in Chinese Higher Education. Eur J Educ 47(2): 228-41. doi:10.1111/j.1465-3435.2012.01520.x.

Mok, Ka Ho, Yu Cheung Wong, and Xiulan Zhang. 2009. When Marketisation and Privatisation Clash with Socialist Ideals: Educational Inequality in Urban China. Int J Educ Dev 29(5): 505-12. doi:10.1016/j.jjedudev.2009.04.011.

Naughton, Barry. 2007. The Chinese Economy: Transitions and Growth. Cambridge: Mit Press 
Nee, Victor. 1989. A Theory of Market Transition: From Redistribution to Markets in State Socialism. Am Sociol Rev 54(5): 663-81. doi:10.2307/2117747.

Nee, Victor. 1992. Organizational Dynamics of Market Transition: Hybrid Forms, Property Rights, and Mixed Economy in China. Adm Sci Q 37(1): 1-27. doi:10.2307/2393531.

Nee, Victor. 1996. The Emergence of a Market Society: Changing Mechanisms of Stratification in China. Am J Sociol 101(4): 908-49. doi:10.2307/2782234.

Nee, Victor, and Cao Yang. 2005. Market Transition and the Firm: Institutional Change and Income Inequality in Urban China. Manag Organ Rev 1(1): 23-56.

NRCSTD, (National Research Center for Science and Technology for Development), and Fafo. 2006. Apendix 1: Sample Selection for the MEDOW Survey. In In Life in Western China - Tabulation Report of Monitoring Social and Economic Development in Western China. Beijing: China Statistics Press.

Obukhova, Elena. 2012. Motivation vs. Relevance: Using Strong Ties to Find a Job in Urban China. Soc Sci Res 41(3): 570-80. doi:10.1016/.jssresearch.2011.12.010.

Piore, Michael J. 1979. Birds of Passage: Migrant Labor and Industrial Societies. Cambridge: Cambridge University Press.

Reza, Sadrel. 2007. Privatisation and Private Sector Growth in China and Russia: A Comparison from the Institutional Perspective. China: An Int J 05(02): 276-307. doi:10.1142/S0219747207000167.

Rubin, Amir, and Dan Segal. 2015. The Effects of Economic Growth on Income Inequality in the US. J Macroecon 45(September): 258-73. doi:10.1016/j.jmacro.2015.05.007.

Schucher, Günter, and Jutta Hebel. 2006. The Emergence of a New "Socialist" Market Labour Regime in China. Working Paper GIGA WP 39/2006. GIGA Working Papers. Rochester, NY: German Institute of Global and Area Studies.

Shue, Vivienne, and Christine Wong. 2007. Paying for Progress in China: Public Finance, Human Welfare and Changing Patterns of Inequality. London and New York: Routledge.

Su, Chi-Wei, Tie-Ying Liu, Hsu-Ling Chang, and Xu-Zhao Jiang. 2015. Is Urbanization Narrowing the Urban-Rural Income Gap? A Cross-Regional Study of China. Habitat Int 48(August): 79-86. doi:10.1016/j.habitatint.2015.03.002.

Sun, Liping. 2008. Societal Transition: New Issues in the Field of the Sociology of Development. Mod Chin 34(1): 88-113. doi:10.2307/20062690

Szelenyi, Ivan, and Eric Kostello. 1996. The Market Transition Debate: Toward a Synthesis? Am J Sociol 101 (4): 1082-96.

Walder, Andrew G. 1996. Markets and Inequality in Transitional Economies: Toward Testable Theories. Am J Sociol 101(4): 1060-73.

Whyte, Martin King. 2010. One Country, Two Societies: Rural-Urban Inequality in Contemporary China. Cambridge: Harvard University Press.

Wu, Che, and Siquan Xie. 2000. The Extent of Marketization of Economic Systems in China. New York: Nova Publishers.

Wu, Haiying. 2007. Changes in Regional Income Disparities and Its Development Trends in China After the Western China Development (西部大开发以来中国地区收入差距的变化及其发展态势). Economy \& Technology, no. 12

Wu, Xiaogang. 2010. Voluntary and Involuntary Job Mobility and Earnings Inequality in Urban China, 1993-2000. Soc Sci Res 39(3): 382-95. doi:10.1016/j.ssresearch.2009.11.003.

Yu, Xie, and Emily Hannum. 1996. Regional Variation in Earnings Inequality in Reform-Era Urban China. Am J Sociol 101(4): 950-92.

Yu, Xie, and Xiang Zhou. 2014. Income Inequality in Today's China. Proc Natl Acad Sci 111(19): 6928-33. doi:10.1073/pnas.1403158111.

Zhang, Junsen, Yaohui Zhao, Albert Park, and Xiaoging Song. 2005. Economic Returns to Schooling in Urban China, 1988 to 2001. J Comp Econ 33(4): 730-52. doi:10.1016/j.jce.2005.05.008.

Zhang, Zhuoni, and Xiaogang Wu. 2016. Occupational Segregation and Earnings Inequality: Rural Migrants and Local Workers in Urban China. Social Science Research. doi:10.1016/j.ssresearch.2016.06.020.

Zhao, Yong, and Wei Qiu. 2012. Policy Changes and Educational Reforms in China: Decentralization and Marketization. On the Horizon 20(4): 313-23. doi:10.1108/10748121211272452.

Zhou, Xueguang, Nancy Brandon Tuma, and Phyllis Moen. 1997. Institutional Change and Job-Shift Patterns in Urban China, 1949 to 1994. Am Sociol Rev 62(3): 339-65. doi:10.2307/2657310.

\section{Submit your manuscript to a SpringerOpen ${ }^{\circ}$ journal and benefit from:}

- Convenient online submission

- Rigorous peer review

- Immediate publication on acceptance

- Open access: articles freely available online

- High visibility within the field

Retaining the copyright to your article

Submit your next manuscript at $\gg$ springeropen.com 